\title{
Capacidade financeira dos municípios paulistas em atender às metas de educação infantil do Plano Nacional de Educação
}

\author{
Maria do Carmo Meirelles Toledo Cruz \\ Escola do Parlamento da Câmara Municipal de São Paulo; Instituto JUS \\ Fátima Fernandes Araújo \\ Secretaria de Desenvolvimento Regional do Estado de São Paulo \\ Carlos Corrêa Leite \\ Secretaria de Desenvolvimento Regional do Estado de São Paulo \\ Fernando Montoro \\ Secretaria de Desenvolvimento Regional do Estado de São Paulo
}

O artigo apresenta estudo sobre a capacidade financeira dos municípios paulistas para atender as metas de educação infantil previstas no anteprojeto de lei do Plano Nacional de Educação para 2011-2020. A partir da base legal de finanças públicas, de projeções populacionais (2012-2020), gastos na educação infantil (2012) e receitas (2012), são analisados os gastos total e per capita em creche, pré-escola e educação infantil e as receitas de cada município. São realizadas projeções sobre o impacto financeiro em 2020 para que os municípios ofertem vagas em creche para $50 \%$ das crianças e em pré-escola para $100 \%$ das crianças. $O$ trabalho identifica que, para atender as metas, os municípios paulistas terão que ampliar seus recursos em 47\%, relativamente a 2012. Mostra também os diferentes graus de esforço para o cumprimento dessas metas: em 164 municípios, significará um incremento superior a $50 \%$ das receitas atuais, sendo que em 43 o incremento ultrapassa $90 \%$.

Palavras-chave: política educacional, educação básica, finanças públicas, execução orçamentária, administração municipal, plano nacional de educação

[Artigo recebido em 14 de setembro de 2018. Aprovado em 8 de março de 2019.] 


\section{Capacidad financiera de los municipios de lo estado de São Paulo para participar en el Plan Nacional de Educación}

El artículo estudia la capacidad financiera de los municipios de São Paulo para cumplir los objetivos de educación de primera infancia previstas en el proyecto de ley del Plan Nacional de Educación 2011-2020. Con base en proyecciones de crecimiento de la población en el periodo 2012-2020, se analizan el gasto total y per cápita en educación de primera infancia y los ingresos de cada municipio. Las proyecciones se realizan sobre el impacto financiero en 2020 para los municipios ofrecen lugares en la guardería para 50\% de los niños y en educación preescolar para $100 \%$ de los niños. El estudio muestra que para cumplir estos objetivos, los municipios de São Paulo deben ampliar los recursos en $47 \%$ en comparación con el gasto de 2012. La investigación señala diferentes grados de esfuerzo de los municipios para cumplir los objetivos establecidos: para 164 municipios, costaría más de 50\% de los recursos actuales e para 43 , el aumento supera el $90 \%$.

Palabras clave: política educativa, educación básica, finanzas públicas, ejecución presupuestaria, administración municipal, plan nacional de educación

\section{Financial capacity in municipalities of São Paulo state to attend the National Education Plan}

The article studies the financial capacity of municipalities in state of São Paulo to meet the goals of early childhood education provided in the draft Bill of the National Education Plan to 2011-2020. The total and per capita spending in daycare and preschool as well the income of each municipality are analyzed from data of population projections to 20122020. Projections are made on the financial impact in 2020 in the municipalities that offer places in daycare for $50 \%$ of children and preschool for $100 \%$ of children. The study shows that the municipalities of state of São Paulo would have to broaden the resources in $47 \%$, compared to spending of 2012, to meet the goal for the access to early childhood education. The research points different degrees of effort of the municipalities to comply with the established goals of the PNE: this effort would cost more than $50 \%$ for 164 municipalities and for 43 , the increase exceeds $90 \%$.

Keywords: educational policy, basic education, public finance, budget execution, municipal administration, national education plan 


\section{Introdução}

Este artigo objetiva dimensionar a capacidade financeira dos municípios paulistas em atendimento às metas propostas para a educação infantil no então anteprojeto de lei do Plano Nacional de Educação (PNE) para o período de 2011-2020. O texto foi aprovado em 2014, como a Lei federal no 13.005/2014, e institucionalizou o PNE de 2014-2024 com as mesmas metas de atendimento à educação infantil estabelecidas no anteprojeto, mas ampliou o prazo destinado à creche até 2024.

Neste trabalho, usa-se o limite temporal do anteprojeto; considera-se o atendimento, até 2020, a 50\% das crianças com idades até três anos (creche) e, até 2016, a 100\% das crianças de quatro a cinco anos (pré-escola). Em 2012, os municípios atendiam, na faixa etária correspondente, a 33\% de crianças na creche e $87 \%$ na pré-escola (FUNDAÇÃo SISTEMA ESTADUAL DE ANÁLISE E DADOS, 2013). As creches e as pré-escolas representam a etapa da educação infantil.

A pesquisa foi realizada no âmbito do projeto Elementos para a Melhoria das Condições de Oferta de Educação Infantil no Estado de São Paulo, a partir de convênio entre a Fundação Prefeito Faria Lima - Centro de Estudos e Pesquisas de Administração Municipal (Cepam); Fundação do Desenvolvimento Administrativo (Fundap); e Fundação Sistema Estadual de Análise de Dados (Seade), firmado em 2013. O estudo parte do conceito de educação como um direito social, em que a intervenção do Estado busca garantir a universalização do acesso, principalmente dos mais pobres (CAVALIERI; PAZELLO, 2004). Por ser a educação infantil da competência dos municípios, com apoios técnico e financeiro dos estados e da União, é certo que a oferta de novas vagas representará gastos adicionais com a educação e trará impacto nas finanças municipais.

O Brasil, desde o PNE de 2001-2010, aprovado pela Lei no 10.172/2001, pactuou atender a $50 \%$ das crianças em creche e $80 \%$ em pré-escola, até 2010 , o que não ocorreu. Em 2012, apenas 92 dos municípios paulistas (15\%) atendiam à meta de creches do PNE, dos quais três com mais de 100 mil habitantes. Na pré-escola, 155 municípios (26\%) atendiam à meta, e todos com menos de 100 mil habitantes (Fundação Prefeito Faria Lima; FundaçÃo do DeSEnVolvimento AdMinistrativo; FundAÇÃo Sistema EstAdUAL dE ANÁlise E DAdOS, 2013). Na educação infantil, analisadas conjuntamente creche e pré-escola, apenas 48 municípios atendiam às duas metas, e todos eram municípios com menos de 100 mil habitantes (FunDAÇÃo Prefeito Faria Lima et al., 2013). A maioria dos que cumprem as metas tem capacidade de arrecadação limitada.

Considerando o intervalo de tempo estabelecido pelo anteprojeto do PNE para que os municípios cumpram as metas (2012 a 2016 para pré-escola, e 2012 a 2020 
para creche), este estudo distribui o esforço financeiro, ano a ano, por meio da oferta de vagas no intervalo de tempo, até o cumprimento total da meta.

A falta de informações agregadas, ou de indicadores que traduzam a situação financeira atual da educação infantil, no conjunto dos municípios paulistas, leva este estudo a responder às seguintes questões: a) Qual é o gasto atual dos municípios com a educação infantil (creche, pré-escola e total)?; b) Qual é o gasto per capita do aluno na educação infantil (creche, pré-escola e total)?; c) Qual é a receita dos municípios para o custeio da educação e educação infantil?; d) Quanto os municípios paulistas gastam de recursos próprios com a educação e com a educação infantil?; e) Quanto os municípios gastarão, de 2013 a 2020, com a educação infantil (creche, pré-escola e total)?; e f) Quais serão as receitas dos municípios, considerando as novas vagas, para custeio da educação infantil (2013 a 2020)?

A análise é relevante por contribuir com a discussão sobre os gastos na educação infantil e os impactos das normatizações nacionais no âmbito subnacional, com vista a reduzir as desigualdades e ampliar o efeito distributivo da educação infantil, garantindo o acesso dos mais pobres. Corrobora estudos realizados por Abrahão (2005), Campanha Nacional pelo Direito à Educação ([201-]), Araújo (2012) e Pinto (2014) e aponta a necessidade de aprimorar o repasse do Fundo de Manutenção e Desenvolvimento da Educação Básica e de Valorização dos Profissionais da Educação (Fundeb) para esta etapa educacional. Também busca contribuir com o debate sobre os gastos na educação infantil e a sua importância na formulação e implementação de políticas educacionais para viabilizar a execução da meta 1 do PNE.

Ademais, o estudo pode ser identificado com a ampliação do interesse teórico pela discussão da importância da educação infantil nos primeiros anos de vida (SOUZA, 2011; Curi; Menezes Filho, 2009; Shonkoff, 2001; HeCKMAN, 2005). Há alguns anos discute-se a importância da educação infantil nos primeiros anos de vida.

Para a neurociência e outras ciências, a formação, nessa etapa, terá impacto no desempenho escolar, na saúde, na produtividade econômica e de cidadania, no futuro (SHONKOFF, 2001). Heckman (2005) aponta que o desenvolvimento intelectual pode ser ampliado até os dez anos; após esse tempo, as ações para compensar os déficits de formação inicial têm maior custo e são menos efetivas; e recuperar tardiamente as habilidades não cognitivas é possível, mas as cognitivas exigem mais esforço.

Outros estudos indicam que os investimentos na infância são importantes para o desenvolvimento de habilidades cognitivas e não cognitivas e influenciam no comportamento e nos traços de personalidade, como sociabilidade, autoestima, persistência e motivação, bem como reduzem a probabilidade de envolvimento com drogas e de participação em atividades criminosas (VEloso, 2011). Para Souza 
(2011), a criança que frequenta pré-escola aprende melhor matemática e português e tem menor atraso escolar. Curi e Menezes Filho (2009, p. 811) mostram que "a pré-escola tem uma relação positiva e significante com a conclusão dos quatro ciclos escolares, com efeito marginal crescente nos três primeiros, e que a creche tem relação positiva e significante apenas com a conclusão do ensino médio e do ensino universitário". Frequentar uma escola infantil de qualidade reduz as desigualdades (CAMPOS, 1997; BARRos et al., 2011; SANTOS, 2015) e impacta no desenvolvimento infantil, em especial das crianças mais vulneráveis.

Apesar desses estudos, verifica-se, nos municípios, a subpriorização dessa etapa de ensino em relação ao ensino fundamental (KRAMER, 2006; CRUz; FARAH; SUGIYAMA, 2014).

O presente artigo está estruturado em cinco partes. A primeira apresenta brevemente a organização da educação, identificando as competências dos entes federados na área. A segunda detalha como é financiada, isto é, como são obtidos os recursos destinados à educação, em particular, pelos municípios. A terceira parte indica a metodologia utilizada e a quarta mostra os resultados obtidos, por meio de tabelas e gráficos explicativos. Finaliza apontando a importância dos estados e da União nos apoios técnico e financeiro aos governos locais para que cumpram suas competências na educação infantil, conforme preconiza a Constituição Federal (CF) de 1988 e o PNE.

\section{Organização da educação no Brasil}

A organização da educação no Brasil é estabelecida pela CF/1988; pela Lei de Diretrizes e Bases da Educação Nacional (LDB), Lei no 9.394/1996; pelo Fundeb, Lei no 11.494/2007; e pelo Plano Nacional de Educação (PNE), entre outras regulamentações.

Hoje, a educação está estruturada em quatro etapas de ensino:

a) educação infantil, com o atendimento em creche (crianças com idades até três anos) e na pré-escola (crianças com quatro e cinco anos);

b) ensino fundamental;

c) ensino médio; e

d) ensino superior.

As três primeiras etapas compõem a educação básica, com atribuições comuns entre as diversas esferas de governo exercidas em regime de colaboração. A $\mathrm{CF} / 1988$, em seu art. 30, inciso $\mathrm{VI}$, define que compete aos municípios manter, em cooperação técnica e financeira com a União e os estados, programas de educação infantil e de ensino fundamental. O art. 211 preconiza que a União, os estados, o 
Distrito Federal e os municípios organizarão, também em regime de colaboração, seus sistemas de ensino. Determina, ainda, as áreas de atuação prioritária dos municípios - ensino fundamental e educação infantil - e dos estados - ensino fundamental e ensino médio.

Assim, a educação infantil (creche e pré-escola) é de competência municipal, por determinação constitucional, com a cooperação técnica e financeira da União e dos estados. Os serviços, por sua vez, podem ser executados pela rede pública (municipal, estadual ou federal), ou privada. Os serviços oferecidos pela rede privada caracterizam-se por duas modalidades: lucrativa, em que os serviços são oferecidos diretamente pelo setor privado e regulados pelo mercado; e sem fins lucrativos, ofertado por instituições comunitárias, confessionais ou filantrópicas, que, muitas vezes, firmam convênios com o poder público e auxiliam na materialização do direito à educação infantil (CRUZ; FARAH; SUGIYAMA, 2014).

O PNE tem como objetivo articular o sistema nacional de educação em regime de colaboração e definir diretrizes, objetivos, metas e estratégias de implementação para assegurar a manutenção e o desenvolvimento do ensino em seus diversos níveis, suas etapas e modalidades, por meio de ações integradas do poder público nas diferentes esferas federativas.

\section{Financiamento da educação}

Para o financiamento da educação, a CF/1988 determina, no art. 212, que a União aplicará, anualmente, nunca menos de 18\% dos recursos; e os estados, o Distrito Federal e os municípios, $25 \%$, no mínimo, da receita resultante de impostos, compreendida a proveniente de transferências, na manutenção e no desenvolvimento do ensino.

Conforme estabelecido na LDB, são recursos públicos destinados à educação os originários da receita de impostos próprios da União, dos estados, do Distrito Federal e dos municípios; receita de transferências constitucionais e outras transferências; receita do salário-educação e de outras contribuições sociais; receita de incentivos fiscais; e outros recursos previstos em lei.

A distribuição dos recursos entre o Distrito Federal, os estados e os municípios é assegurada mediante a criação do Fundeb, no âmbito de cada estado e do Distrito Federal, com natureza contábil.

Esses fundos estaduais são constituídos por $20 \%$ dos recursos provenientes de: a) arrecadação dos impostos próprios dos estados e Distrito Federal (Imposto sobre Transmissão Causa Mortis e Doação de quaisquer bens ou direitos - ITCMD; Imposto sobre operações relativas à Circulação de Mercadorias e sobre Prestações 
de Serviços de Transporte Interestadual e Intermunicipal e de Comunicação - ICMS; e Imposto sobre Propriedade de Veículos Automotores - IPVA); b) receitas de transferências constitucionais a estados e ao Distrito Federal (Fundo de Participação dos Estados - FPE e Imposto sobre Produtos Industrializados proporcional às exportações - IPI-Exportação); c) receitas de transferências constitucionais a municípios (Fundo de Participação dos Municípios - FPM e quota-parte dos municípios na arrecadação do Imposto sobre a Propriedade Territorial Rural - ITR, do IPVA, do ICMS e do IPI-Exportação).

O Fundeb é distribuído entre cada estado e seus municípios, proporcionalmente ao número de alunos das diversas etapas e modalidades da educação básica presencial, matriculados nas respectivas redes, nos respectivos âmbitos de atuação prioritária (CF, art. 60, II do ADCT). A lei determina que os recursos recebidos dos fundos sejam aplicados pelos estados e municípios exclusivamente nos respectivos âmbitos de atuação prioritária. A distribuição é realizada por meio de fatores de ponderação entre as etapas e modalidades. Segundo a Lei no 11.494/2007, em seu artigo 13, inciso I, as ponderações devem levar em consideração o custo das etapas e segmentos e tipo de estabelecimento, a partir de estudos realizados pelo Instituto Nacional de Estudos e Pesquisas Educacionais Anísio Teixeira.

A União complementa os recursos dos fundos sempre que, no Distrito Federal e em cada estado, o valor por aluno não alcançar o mínimo definido nacionalmente. Dispõe, ainda, de até $10 \%$ da complementação do fundo para programas direcionados à melhoria da qualidade da educação.

As quotas estaduais e municipais de arrecadação da contribuição social do salário-educação são distribuídas proporcionalmente ao número de alunos matriculados na educação básica, nas respectivas redes públicas de ensino.

A educação oferece também atendimento ao educando em todas as etapas da educação básica, por meio de programas suplementares de material didáticoescolar, transporte, alimentação e assistência à saúde. Os programas suplementares de alimentação e assistência à saúde são financiados com recursos provenientes de contribuições sociais e outros recursos orçamentários.

As receitas municipais obrigatórias para a educação estão definidas, para fins deste estudo e em consonância com os preceitos legais discorridos anteriormente, pela composição dos elementos apresentados no Quadro 1. Envolvem: a) receita própria dos impostos municipais; b) receita de transferências constitucionais de impostos federais e estaduais; e c) receita de transferências intergovernamentais, vinculadas à educação. 


\section{Quadro 1 - Principais receitas municipais destinadas à educação}

\begin{tabular}{|c|c|c|c|c|c|}
\hline $\begin{array}{l}\text { Receita } \\
\text { própria de } \\
\text { impostos } \\
(25 \%)\end{array}$ & \multicolumn{2}{|c|}{$\begin{array}{l}\text { Receita de transferências } \\
\text { constitucionais de impostos } \\
\text { (5\%) }\end{array}$} & \multicolumn{3}{|c|}{ Transferências vinculadas à educação (100\%) } \\
\hline Municipais & Federais & Estaduais & Intergovernamentais & Federais & Estaduais \\
\hline IPTU & FPM & $\begin{array}{l}\text { Quota- } \\
\text { parte do } \\
\text { ICMS }\end{array}$ & Fundeb & FNDE & $\begin{array}{l}\text { Convênios } \\
\text { com o } \\
\text { estado }\end{array}$ \\
\hline ISS & $\begin{array}{l}\text { Quota-parte } \\
\text { do ITR }\end{array}$ & $\begin{array}{l}\text { Quota- } \\
\text { parte do } \\
\text { IPVA }\end{array}$ & $\begin{array}{l}\text { Fundeb - } \\
\text { Complemento }\end{array}$ & $\begin{array}{l}\text { Convênios } \\
\text { com a } \\
\text { União }\end{array}$ & \\
\hline ITBI & $\begin{array}{l}\text { Desoneração } \\
\text { das } \\
\text { exportações } \\
\text { (Lei Kandir) }\end{array}$ & $\begin{array}{l}\text { Quota- } \\
\text { parte do IPI- } \\
\text { Exportação }\end{array}$ & & & \\
\hline
\end{tabular}

Fonte: elaboração própria com base em Montoro (2013).

Da receita própria dos impostos municipais, 25\% devem ser destinados à educação, por determinação constitucional. A receita envolve o Imposto sobre Propriedade Territorial e Predial Urbana (IPTU), Imposto sobre Serviços de Qualquer Natureza (ISS) e Imposto sobre a Transmissão de Bens Inter Vivos (ITBI).

Também deve ser destinada à educação $25 \%$ da receita advinda de transferências constitucionais de impostos federais e estaduais. Parcela desse montante (20\%) já é descontada para a formação do Fundeb - considerada transferência intergovernamental - e utilizada na educação, como será visto adiante. Assim, do valor das transferências de impostos aos municípios, resta ainda 5\% a ser utilizado na educação. Entre as transferências federais aos municípios, estão o Fundo de Participação dos Municípios (FPM), a quota-parte do ITR e do Imposto sobre Operação Financeira (IOF) Ouro e a Desoneração das Exportações da Lei Complementar no 87/1996; e, entre as transferências estaduais, a quota-parte do ICMS, do IPVA e do IPI-Exportação.

Por fim, existem as transferências intergovernamentais, vinculadas à educação. $\mathrm{O}$ Fundeb é a mais significativa dessas receitas, e os governos federal e estaduais ainda organizam programas para a educação, atendendo aos dispositivos legais. Neste estudo, focalizam-se apenas os programas federais e estaduais de apoio à educação infantil que disponibilizam recursos financeiros aos municípios e estão incluídos nas receitas de repasse do Fundo Nacional de Desenvolvimento da Educação (FNDE) e 
de convênios (federal e estadual) e devem ser utilizados totalmente na educação.

Há os seguintes programas federais de apoio à educação infantil: Programa Nacional de Alimentação Escolar (Pnae), Programa Dinheiro Direto na Escola (PDDE), Programa Nacional de Apoio ao Transporte do Escolar (Pnate), Programa Nacional Biblioteca da Escola (PNBE), Programa Nacional de Reestruturação e Aquisição de Equipamentos para a Rede Escolar Pública de Educação Infantil (Prolnfância), Caminhos da Escola, Programa Nacional Escolas de Gestores de Educação Básica Pública, Plano de Ações Articuladas (PAR) e Brasil Carinhoso. No Estado de São Paulo, há o Programa Educacional Estado/Município/Educação Infantil (Paem)/ Educação Infantil, também chamado de Programa Creche Escola, de apoio financeiro a investimentos em creche nos municípios (construção, mobiliário e utensílios).

\section{Metodologia do trabalho}

Para estimar a capacidade financeira dos municípios no atendimento às metas de educação infantil, foram realizados cálculos e projeções a partir da legislação de finanças públicas na educação e das seguintes bases de dados: a) Sistema de Informações sobre Orçamentos Públicos em Educação (Siope), 2012 - Dados Financeiros - Relatórios Municipais (Demonstrativo da Função Educação, Demonstrativo Fundef/Fundeb); b) Secretaria do Tesouro Nacional (STN) - Finanças do Brasil (Finbra), 2012 - Dados Financeiros; c) Fundação Seade - Estimativas de população nas faixas etárias até três anos e de quatro a cinco e de matrículas (2013 a 2020).

A base de dados financeiros do STN não disponibiliza os dados da educação infantil desagregados por creche e pré-escola. Para apresentá-los separadamente, foram utilizados os dados do Siope para complemento das informações, uma vez que esse sistema os traz desagregados. Informações de municípios que constavam no Siope e não apareciam no STN também foram aproveitadas, de maneira a obter o maior número de municípios para análise. Esse procedimento foi possível por se tratar de informações de execução orçamentária, pois não há variação nos dados. Foram considerados 603 municípios do estado, e excluídos 42, por falta das informações necessárias. Portanto, as análises foram feitas com base em mais de 93\% dos municípios paulistas.

A projeção de vagas, ano a ano, foi feita pela Fundação Seade, pelo método linear, a partir da projeção populacional na idade. Nos cálculos, consideram-se as vagas ofertadas pelas redes públicas municipais e conveniadas. 
A partir da base de dados, foi estruturada a matriz de cálculos para responder às indagações iniciais aqui apresentadas. Todos os cálculos foram realizados para cada um dos municípios, o que permitiu análises individuais, por recortes populacionais e nível de gasto. Os respectivos valores totais do estado foram obtidos pelo somatório de todos os municípios do universo trabalhado.

Os procedimentos para os cálculos do ano de 2012 envolveram:

- Receita municipal para a educação: somatório de $25 \%$ das receitas de impostos próprios; $5 \%$ das transferências constitucionais da União e do estado; e transferências intergovernamentais vinculadas à educação (Fundeb, FNDE e convênios federais e estaduais).

- Gasto municipal com educação: foram utilizadas as despesas liquidadas total da função Educação.

- Gasto municipal com educação infantil (creche e pré-escola): foram utilizadas as despesas liquidadas da educação infantil (subfunção 365).

- Gasto per capita: foi obtido pela divisão do valor das despesas liquidadas pela quantidade de matrículas na etapa e segmento educacional.

- Receita de transferências para a educação infantil: foi obtida pelo somatório das transferências do Fundeb, do FNDE e de convênios (proporcionais à etapa).

- Uma vez que a receita de transferência do Fundeb não se encontra discriminada por etapa educacional, optou-se por considerar a mesma proporção dos gastos, que estão discriminados por etapa. Foram apropriadas da mesma forma as transferências do FNDE e de convênios.

- Recursos próprios municipais gastos com a educação infantil: despesas menos as receitas de transferências intergovernamentais.

- A partir da coleta dos dados, foi realizada a projeção financeira de 2013 a 2020, utilizando:

- Gastos com educação infantil: a partir da projeção da Fundação Seade de população na faixa etária para creche, em 2020, e para pré-escola, em 2016, foi calculado o número das vagas necessárias a serem disponibilizadas para cumprimento do $\mathrm{PNE}$, respectivamente, 50\% das crianças em creches e $100 \%$ em pré-escolas. Do total de vagas a serem criadas, foram subtraídas as vagas oferecidas em 2012 e o saldo distribuído pelo método linear, ano a ano, até 2016, para a pré-escola, e 2020 para creche. O total de vagas de cada ano foi obtido pela soma das vagas existentes mais a quantidade de vagas a ser incrementada no ano. As vagas de pré-escola, em 2016, foram mantidas inalteradas até 2020. 
- O cálculo dos gastos resulta da multiplicação da quantidade de vagas a serem disponibilizadas a cada ano pelo valor per capita de 2012. Todas as projeções financeiras foram feitas baseadas no valor corrente desse ano, e o incremento financeiro anual resulta apenas do aumento da quantidade de vagas.

- Receita municipal para a educação: somatório de $25 \%$ das receitas de impostos (valores fixos de 2012); 5\% das transferências constitucionais da União e do estado (valores fixos de 2012); transferências intergovernamentais do Fundeb (valor per capita de 2012, multiplicado pela quantidade de vagas do ano para educação infantil e valor fixo para o ensino fundamental), do FNDE e de convênios federal e estaduais (valores fixos de 2012). Note-se que, na projeção feita, somente a transferência do Fundeb aumenta ano a ano, resultado do crescimento da quantidade de vagas a serem atendidas.

- Recursos próprios a serem gastos com a educação e educação infantil: projeção dos gastos com educação menos a projeção das receitas de transferências do Fundeb no ano.

\section{Análise dos dados}

$\mathrm{Na}$ análise dos dados, optou-se por identificar as receitas municipais com educação e educação infantil, correlacionando-as com os gastos totais e o gasto médio per capita de creche, pré-escola e educação infantil, por grupo de municípios de mesmo porte populacional.

Também foi identificado em que magnitude as transferências federais e estaduais cobrem os gastos municipais com essa etapa de ensino. A partir dessas informações, foram realizadas projeções anuais dos gastos com educação Infantil e das receitas para essa etapa de ensino e estimado o esforço financeiro dos municípios para atingir as metas previstas no PNE com relação ao acesso à educação infantil.

\section{Receitas e gastos com educação}

As receitas e despesas com educação, compostas pelos valores agregados dos 603 municípios paulistas, podem ser observadas nas Tabelas 1 e 2.

Em relação às receitas, nota-se a importância das transferências do Fundeb, que, em 2012, representaram 47\% da receita, e as receitas de impostos próprios e transferências constitucionais, que representaram $44 \%$ da receita obrigatória para a educação. 
Tabela 1 - Composição das receitas obrigatórias para a educação e educação infantil nos municípios paulistas - 2012 (R\$ milhões e percentual)

\begin{tabular}{|c|c|c|c|c|c|c|}
\hline Item & $\begin{array}{l}25 \% \text { das } \\
\text { receitas } \\
\text { de } \\
\text { impostos }\end{array}$ & $\begin{array}{l}5 \% \text { das } \\
\text { transferências } \\
\text { de impostos } \\
\text { aos } \\
\text { municípios }\end{array}$ & Fundeb & FNDE & $\begin{array}{l}\text { Transferências } \\
\text { de convênios }\end{array}$ & $\begin{array}{l}\text { Total da } \\
\text { receita } \\
\text { obrigatória } \\
\text { para } \\
\text { educação }\end{array}$ \\
\hline \multirow{2}{*}{ Educação } & 8.977 & 2.055 & 11.817 & 2.064 & 268 & 25.180 \\
\hline & $36 \%$ & $8 \%$ & $47 \%$ & $8 \%$ & $1 \%$ & $100 \%$ \\
\hline $\begin{array}{l}\text { Educação } \\
\text { infantil }\end{array}$ & & & 4.383 & 765 & 94 & 5.242 \\
\hline
\end{tabular}

Fonte: elaboração própria com base em Siope (2013) e STN (2013).

Em relação às despesas com educação, observa-se que $\mathrm{R} \$ 10.129$ milhões foram gastos com a educação infantil, o que representa, em média, 35\% dos gastos totais, indicando a priorização do ensino fundamental, seguindo a trajetória anterior da política educacional, que deu ênfase ao ensino fundamental (PINTO, 2014; ARRETCHE, 1998).

Tabela 2 - Composição das despesas (liquidadas) com educação nos municípios paulistas - 2012 (R\$ milhões e percentual)

\begin{tabular}{lllll}
\multicolumn{2}{l}{ Educação infantil } & & $\begin{array}{l}\text { Ensino } \\
\text { fundamental } \\
\text { e outros }\end{array}$ & $\begin{array}{l}\text { Total - } \\
\text { educação } \\
\text { básica }\end{array}$ \\
\hline Creche & Pré-escola & Total & 18.901 & 29.030 \\
\hline 4.762 & 5.367 & 10.129 & $65 \%$ & $100 \%$ \\
\hline $16 \%$ & $18 \%$ & $35 \%$ & &
\end{tabular}

Fonte: elaboração própria com base em Siope (2013) e STN (2013).

Finalmente, observa-se que o gasto total com a educação, nesse ano, no conjunto dos 603 municípios, foi de $\mathrm{R} \$ 29.030$ milhões (Tabela 2) e as receitas obrigatórias para gasto na educação atingiram $\mathrm{R} \$ 25.180$ milhões (Tabela 1). Os municípios despenderam, portanto, $\mathrm{R} \$ 3.849$ milhões além dos gastos obrigatórios, ou seja, um acréscimo de mais de $15 \%$ do total das receitas destinadas à educação.

Ademais, foi também analisado o comprometimento das receitas de transferências recebidas para a educação infantil em relação ao gasto nessa etapa de ensino. As receitas de transferências para a educação infantil ( $R$ \$ 5.242 milhões) representam $52 \%$ do total dos respectivos gastos ( $R \$ 10.129$ milhões): as receitas 
do Fundeb cobrem 43\%, as transferências do FNDE, 8\%, e, as de convênios, $1 \%$. Os municípios complementam, portanto, $48 \%$ dos recursos necessários para a manutenção da educação infantil. As informações apresentadas corroboram outros estudos que identificam o gasto municipal com esse segmento educacional maior do que o repasse do Fundeb (CAMPANHA NACIONAL PELO DiREITo à EdUCAÇÃo, [201-]; ABRAHÃO, 2005; PINTO, 2014).

O gasto médio com educação infantil representou cerca de $9 \%$, e a educação correspondeu a $26 \%$ das receitas correntes dos 603 municípios analisados. O total dos municípios do Estado de São Paulo ultrapassou o percentual obrigatório de gastos com a educação.

O gasto médio per capita da educação infantil foi de $R \$ 6.791,82$, sendo $R \$$ $7.082,97$ para creche e $\mathrm{R} \$ 6.552,86$ para a pré-escola, em 2012 , com grandes diferenças entre os municípios. Chama a atenção a proximidade dos valores de creche e pré-escola, uma vez que, pelo senso comum, e pelo Custo Aluno Qualidade Inicial (CAQi) (Campanha, [200-]), os custos de creche deveriam ser maiores do que o da pré-escola.

Consultados os gestores de alguns municípios a respeito desses valores, as respostas foram diferenciadas, variando desde a inadequada apropriação dos gastos no Sistema de Informações sobre Orçamentos Públicos em Educação (Siope); convênios com instituições que oferecem vagas a um custo menor; opção de alguns municípios ofertarem vagas parciais em creche para ampliar o atendimento e diluir o gasto unitário; e a política de contratação do pessoal (não exigência de magistério para os profissionais).

Araújo (2012) também encontra informações imprecisas nos custos da educação, e há uma subdeclaração no preenchimento dos dados, pelas equipes municipais, com gastos em educação infantil. De fato, esse é um tópico que merece aprofundamento, assim como a análise da ampliação de vagas parciais em creches. ${ }^{1}$

Para verificar se o porte do município tem influência no perfil dos gastos per capita, foi feita a distribuição das localidades por porte populacional. O agrupamento procurou reproduzir o perfil populacional do conjunto dos municípios no estado: a) Grupo 1 - de 1 a 2.000 habitantes; b) Grupo 2 - de 2001 a 4.000; c) Grupo 3 - de 4001 a 8.000; d) Grupo 4 - de 8001 a 16.000; e) Grupo 5 - de 16.001 a 32.000; f)

\footnotetext{
${ }^{1}$ Em 2012, os valores do Fundeb para os municípios paulistas, relativos à creche e pré-escola integral eram R\$ $3.688,17$ e para a creche e pré-escola parcial, $\mathrm{R} \$ 2.269,64$ e $\mathrm{R} \$ 2.837,06$, respectivamente. Às conveniadas, os valores do Fundo eram $\mathrm{R} \$ 3.120,76$ para a creche integral e $\mathrm{R} \$ 2.269,64$ para a parcial e, na pré-escola, $\mathrm{R} \$$ $3.688,17$ e 2.837,06, respectivamente. Deve ser destacado que, tanto para a rede pública como conveniada, há um distanciamento entre os gastos e os valores recebidos do Fundeb na educação infantil, corroborando estudos de Almeida (2012).
} 
Grupo 6 - de 32.001 a 64.000; g) Grupo 7 - de 64.001 a 128.000; h) Grupo 8 - de 128.001 a 256.000; i) Grupo 9 - de 256.001 a 512.000; j) Grupo 10 - acima de 512.000 habitantes.

O Gráfico 1 mostra que os municípios com população abaixo de 2 mil e mais de 500 mil habitantes têm gasto per capita maior do que o conjunto dos municípios, em creche, pré-escola e educação infantil. Talvez essa diferença em relação ao conjunto seja justificada pelo custo de mão de obra nos municípios maiores e a falta de ganhos de escala dos municípios menores, principalmente nos gastos com pessoal administrativo e gerencial. Arretche (2012) e Bremaeker (2011) mostram que, para manter os serviços com a mesma qualidade ofertada na época do antigo Fundo de Manutenção e Desenvolvimento do Ensino Fundamental e de Valorização do Magistério (Fundef), os municípios, em especial as pequenas localidades, precisam desembolsar mais recursos.

Gráfico 1 - Gasto per capita, por grupo populacional, em creche, pré-escola e total de educação infantil - 2012 (R\$)

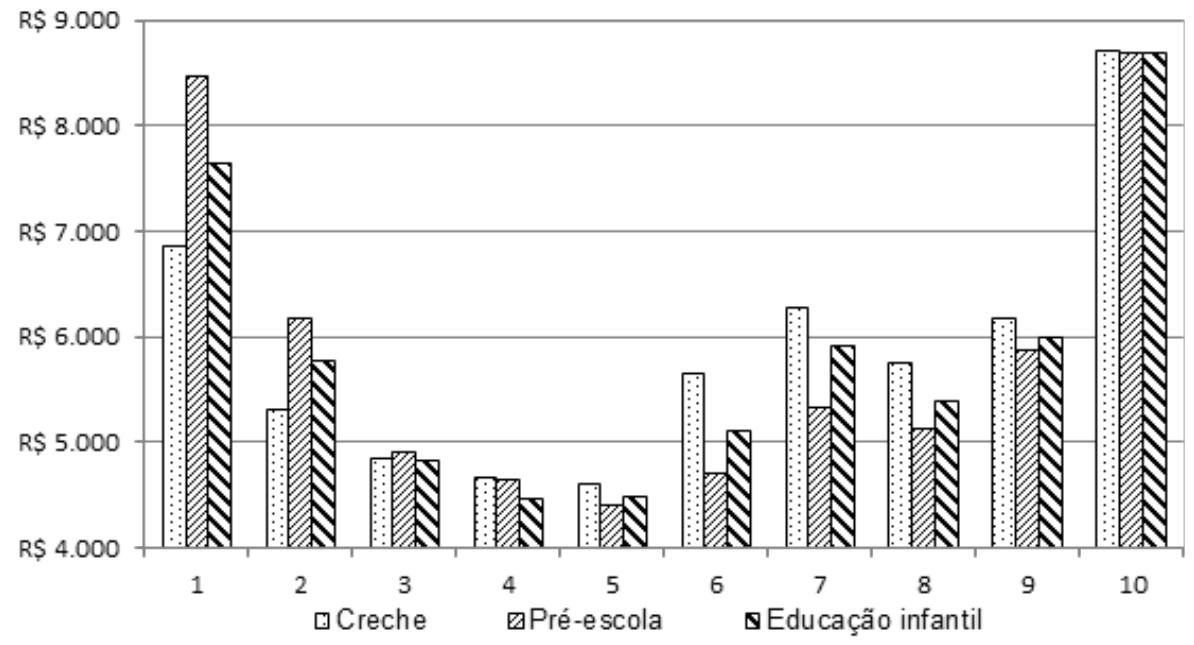

Fonte: elaboração própria com base em Siope (2013), Seade (2013) e STN (2013).

A partir da análise dos gastos em 2012, foram realizadas as projeções de gastos até 2020 .

\section{Projeção anual de gastos e receitas em educação}

A Tabela 3 apresenta os valores anuais, seguindo uma projeção com crescimento linear de atendimento de vagas para cumprimento das metas de $50 \%$ das crianças em creche em 2020 e universalizar a pré-escola em 2016. 
Tabela 3 - Estimativas de despesa com educação infantil, receitas municipais para a educação e transferências (Fundeb) e recursos próprios para a educação infantil (R\$ milhões)

\begin{tabular}{|c|c|c|c|c|}
\hline Ano & $\begin{array}{l}\text { Despesa com } \\
\text { educação } \\
\text { infantil }\end{array}$ & $\begin{array}{l}\text { Total de } \\
\text { receitas } \\
\text { municipais } \\
\text { para a } \\
\text { educação } \\
\text { básica (1) }\end{array}$ & $\begin{array}{l}\text { Receitas de } \\
\text { transferências } \\
\text { para a } \\
\text { educação } \\
\text { infantil - } \\
\text { Fundeb }\end{array}$ & $\begin{array}{l}\text { Recursos } \\
\text { próprios } \\
\text { municipais } \\
\text { necessários } \\
\text { para a } \\
\text { educação } \\
\text { infantil }\end{array}$ \\
\hline 2012 & 10.129 & 25.180 & 4.383 & 5.746 \\
\hline 2013 & 10.978 & 25.569 & 4.742 & 6.237 \\
\hline 2014 & 11.828 & 25.929 & 5.101 & 6.727 \\
\hline 2015 & 12.677 & 26.287 & 5.460 & 7.217 \\
\hline 2016 & 13.526 & 26.647 & 5.819 & 7.707 \\
\hline 2017 & 13.870 & 26.803 & 5.975 & 7.895 \\
\hline 2018 & 14.214 & 26.959 & 6.132 & 8.082 \\
\hline 2019 & 14.558 & 27.115 & 6.288 & 8.270 \\
\hline 2020 & 14.903 & 27.272 & 6.445 & 8.458 \\
\hline $\begin{array}{l}\text { Variação } \\
\text { 2012/2020 }\end{array}$ & $47 \%$ & $8 \%$ & $47 \%$ & $47 \%$ \\
\hline
\end{tabular}

(1) Fundeb proporcional para educação infantil e fixo para o ensino fundamental. Fonte: elaboração própria com base em STN (2013) e Siope (2013).

A projeção aponta crescimento de $47 \%$ das despesas com educação infantil até 2020. Esses gastos, que representavam 35\% das receitas para educação em 2012, deverão alcançar 55\%, em 2020, nas hipóteses consideradas.

A projeção anual de receitas municipais para o total da educação, por sua vez, gera crescimento de apenas $8 \%$ até 2020 , partindo de $\mathrm{R} \$ 25.180$ milhões, em 2012,

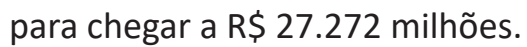

As estimativas, portanto, apontam a necessidade de incremento de receitas. A melhoria de receitas ocorre com aumento de recursos para o financiamento da educação, em parte por meio da ampliação das transferências. Para identificar seu montante, foram considerados apenas os valores de transferência do Fundeb, por ser receita definida e certa (as demais receitas de transferência - FNDE e convênios - são negociáveis ou incertas). As receitas de transferências do Fundeb somaram, 
em 2012, R\$ 4.383 milhões, e a projeção para 2020, com o incremento das novas vagas, é de $R \$ \frac{1}{645}$ milhões.

Assim, para fazer frente aos novos gastos com a educação infantil, os municípios deverão aportar R\$ 8.458 milhões em 2020, contra R\$ 5.746 milhões em 2012, crescendo $47 \%$.

\section{Estimativa do esforço necessário por município}

A divisão desse aporte de recursos entre os 603 municípios do estudo, isto é, o esforço financeiro próprio para cumprir as metas preconizadas pelo anteprojeto do PNE, até 2020, está representado no Gráfico 2. Para 318 municípios, a educação infantil custará entre $10,1 \%$ a 50\% a mais dos valores gastos em 2012 . O incremento dos gastos com educação infantil em patamares acima de 50\% ocorrerá em 164 municipalidades. Dessas, 81 municípios, acima de 70\%, e 43 exigiriam incremento de receitas acima de $90 \%$. Destaca-se um pequeno grupo de 43 municípios que não terá gastos adicionais.

Gráfico 2 - Esforço financeiro adicional para cumprir as metas de creche e pré-escola

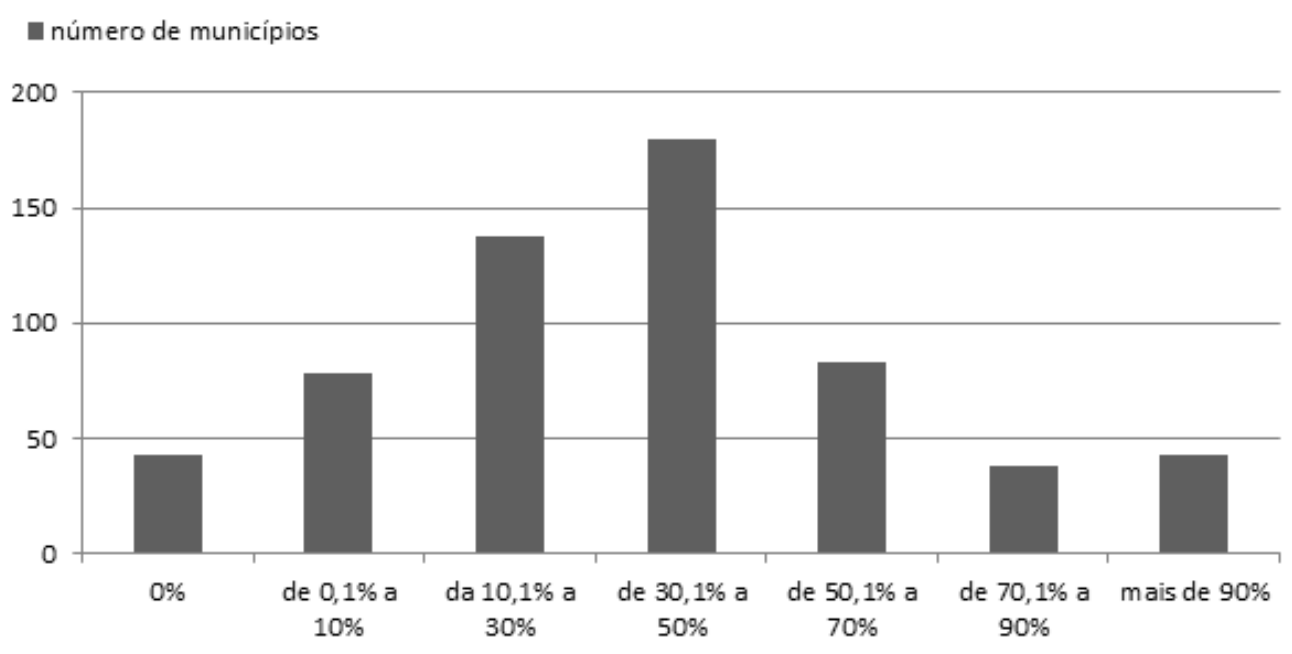

Fonte: Cepam et al. (2013)

Existem municípios (grandes e pequenos) com gastos elevados (acima de $10 \%$ das receitas correntes), que precisarão fazer investimentos elevados para cumprir a meta do PNE. Há ainda municípios grandes, com gastos abaixo da média, que terão de fazer um esforço acima de $70 \%$ para cumprir a meta. 
De fato, a análise do incremento de gastos com a oferta de novas vagas mostra graus de esforços individuais bastante diferenciados para os municípios. Em um primeiro momento, pensou-se que os municípios com maior investimento em educação infantil tivessem que fazer esforço menor, em percentuais de gasto das receitas municipais, para a cobertura das novas vagas, e que os municípios de grande porte tivessem que fazer esforço maior, devido à grande demanda. Os dados mostraram, no entanto, que nesse aspecto não existe um padrão por porte ou por outra característica qualquer. Tampouco a localização em região metropolitana e ter receitas municipais elevadas explicam a grande diferença nos valores per capita de gastos em educação infantil.

Outro aspecto que mereceu atenção no estudo para os municípios viabilizarem as metas do PNE foram as parcerias com instituições do terceiro setor. A rede de instituições comunitárias, confessionais ou filantrópicas, sem fins lucrativos, conveniadas com o poder público, tornou-se fundamental no atendimento ao público da educação infantil. A possibilidade de financiamento de vagas nessas instituições, com recursos do Fundeb, permitiu que 201 municípios optassem por um modelo híbrido de oferta de vagas - públicas e conveniadas - para garantir o acesso à creche e 93 municípios, à pré-escola (Tabela 4).

Tabela 4 - Municípios com creches e pré-escolas conveniadas - 2012

\begin{tabular}{|c|c|c|c|c|c|c|c|c|c|}
\hline $\begin{array}{l}\text { Porte } \\
\text { populacional } \\
\text { (hab.) }\end{array}$ & $\begin{array}{l}\text { Quantidade } \\
\text { de } \\
\text { municípios }\end{array}$ & $\begin{array}{l}\text { Municípios } \\
\text { com } \\
\text { matrículas } \\
\text { conveniadas } \\
\text { em creche }\end{array}$ & $\%$ & $\begin{array}{l}\text { Matrículas } \\
\text { conveniadas } \\
\text { em creche }\end{array}$ & $\%$ & $\begin{array}{l}\text { Municípios } \\
\text { com } \\
\text { matrículas } \\
\text { conveniadas } \\
\text { em pré- } \\
\text { escola }\end{array}$ & $\%$ & $\begin{array}{l}\text { Matrículas } \\
\text { conveniadas } \\
\text { em pré- } \\
\text { escola }\end{array}$ & $\%$ \\
\hline $\begin{array}{l}\text { menos de } \\
100.000\end{array}$ & 529 & 142 & 27 & 15.736 & 7 & 43 & 8 & 2.163 & 7 \\
\hline $\begin{array}{l}100.001- \\
200.000\end{array}$ & 35 & 24 & 69 & 9.003 & 4 & 21 & 60 & 3.002 & 10 \\
\hline $\begin{array}{l}\text { mais de } \\
200.000\end{array}$ & 39 & 35 & 90 & 210.508 & 89 & 29 & 74 & 25.932 & 83 \\
\hline Total & 603 & 201 & 33 & 235.247 & 100 & 93 & 15 & 31.097 & 100 \\
\hline
\end{tabular}

Fonte: elaboração própria com base em Fundação Seade (2013).

Observa-se que há frequência maior de municípios que utilizam a rede conveniada em creche do que em pré-escola. Quanto maior é o município, mais essa parceria é utilizada: daqueles com menos de 100 mil habitantes, $27 \%$ mantêm a rede conveniada em creche, garantindo 15.756 matrículas; dos municípios com mais de 200 mil, 90\% mantêm a rede conveniada em creche, possibilitando 210.508 matrículas. 
Tabela 5 - Matrículas em creches e pré-escolas conveniadas e públicas - 2012

\begin{tabular}{lllll}
\hline & Creche & $\%$ & Pré-escola & $\%$ \\
\hline Conveniadas & 235.247 & 35 & 31.097 & 4 \\
\hline Públicas & 437.022 & 65 & 787.960 & 96 \\
\hline Total & 672.269 & 100 & 819.057 & 100 \\
\hline
\end{tabular}

Fonte: elaboração própria com base em Fundação Seade (2013).

Em 2012, a rede conveniada representou 35\% do total das matrículas em creche oferecidas pelos municípios paulistas e $4 \%$ do total das matrículas em pré-escola (Tabela 5).

O número de matrículas em creche conveniada e percentual de crianças atendidas nessas unidades indicam a importância dessa prática na materialização da política municipal de creches (CRUZ; FARAH; SUGIYAMA, 2014). Os dados mostram a importância histórica que organizações da sociedade civil assumem no segmento educacional de creches, como alternativa das gestões municipais para o aumento da oferta de vagas.

\section{Considerações finais}

Observa-se que é necessário ampliar as alternativas de financiamento, para viabilizar o incremento de vagas em creche e pré-escola. Os gastos com essa etapa de ensino são maiores do que os valores repassados pelo Fundeb (com vigência até 2020). O reconhecimento dessa dificuldade exige que sejam feitas mudanças na estrutura de financiamento da educação.

Para melhor entendimento da educação municipal, é necessária a análise de dados das demais etapas de ensino (fundamental) para verificar as alternativas de financiamento. Alguns gestores municipais, em função dos Termos de Ajuste de Conduta (TACS) para ampliação do acesso à educação infantil, em especial à creche, têm ponderado a opção de não atender mais diretamente ao $2^{\circ}$ ciclo do ensino fundamental (6o ao 9a ano) e centrar esforços na educação infantil e no $1^{\circ}$ ciclo do ensino fundamental (1으 ao 5으 ano).

$\mathrm{Na}$ análise aqui realizada, foram feitas estimativas de crescimento da população, da necessidade de vagas e do impacto financeiro. Entretanto, há outros aspectos a serem estudados, para verificar a viabilidade de novas ações municipais nessa etapa de ensino. Como exemplos, analisar os orçamentos municipais considerando a Lei de Responsabilidade Fiscal (limite de gastos com pessoal, aumento do número de profissionais, ampliação orçamentária etc.); a possibilidade de contratação de 
terceiros; os Planos de Cargos, Carreiras e Remuneração; a existência de espaço físico e infraestrutura adequados; a possibilidade de parcerias com instituições; a quantidade de crianças em situação de vulnerabilidade atendidas; a oferta de vagas em meio período, que isenta o prefeito de ações judiciais, mas não atende ao direito dos pais que trabalham.

Essas informações podem embasar um diagnóstico mais efetivo para a formulação de uma ação estratégica na educação infantil, seguindo o regime de colaboração previsto na legislação brasileira. Ressalta-se que a colaboração técnica e financeira da União e do Estado de São Paulo que envolva as esferas federal e estadual no apoio aos municípios para atender às metas do PNE para implementar a política de educação infantil, por meio de programas como Creche Escola, Prolnfância, Brasil Carinhoso, PDDE, entre outros, ajuda, mas não é suficiente para viabilizar as metas do PNE (CRUZ, 2017). O apoio financeiro da União e do estado na construção ou em reformas de unidades escolares e no fornecimento de equipamentos representa um avanço na política, mas esses investimentos gerarão futuras despesas de custeio dependentes de fontes de financiamento. Essas ações de colaboração deveriam, ainda, considerar as diferentes características dos municípios.

Além disso, o estudo aqui realizado deve dialogar com outros trabalhos, como o Custo Aluno Qualidade Inicial, as análises do Ministério da Educação (MEC) e do Instituto de Pesquisa Econômica Aplicada (Ipea), entre outros. É importante salientar que a educação era a terceira prioridade dos prefeitos da gestão 20132016, para os municípios paulistas (SALOMÃo et al., 2014). Das 367 localidades participantes da pesquisa, 274 (75\%) colocaram a educação como uma das quatro primeiras prioridades da administração e, destas, o principal foco era a expansão de creches e pré-escolas (74\%). Assim, há interesse dos executivos municipais em ampliar o acesso à educação infantil, com os apoios técnico e financeiro do estado e da União, para consolidar o acesso a essa etapa de ensino no Estado de São Paulo, conforme preconizado na CF/1988.

Outro ponto a ser destacado refere-se ao Sistema de Informações sobre Orçamentos Públicos em Educação. Há avanços significativos na produção e disponibilização de dados. Mas como são declaratórios, é necessário, ainda, discutir com os municípios a qualidade das informações e a apropriação dos gastos na educação, uma vez que se percebe discrepância nos dados analisados. Destaca-se a importância de investimentos em bases de dados abertas com informações de todos os municípios brasileiros que permitam a visão particularizada das políticas públicas por localidade e consolidada dos estados, das regiões e do Brasil.

Deve-se advertir que o PNE preconiza a ampliação do acesso à educação 
infantil e melhoria da qualidade do atendimento por meio da rede pública. Neste trabalho, não foi possível avançar na avaliação da qualidade, mas apenas restringir-se aos aspectos quantitativos de acesso à creche e pré-escola e dos gastos incrementais para viabilizar as novas vagas. A melhoria da qualidade da educação infantil ofertada faz-se cada vez mais necessária e é essencial para o desenvolvimento infantil.

Outras pesquisas podem contribuir com o debate, ao atualizar este estudo para o horizonte temporal do PNE aprovado (2014 a 2024) e identificar o impacto nas receitas e despesas em educação infantil a partir da Emenda Constitucional no 95/2016, que limita por 20 anos os gastos públicos com as áreas sociais e devido à desaceleração da economia brasileira pós 2015.

Novos estudos podem analisar, ainda, a evolução da estrutura demográfica no Brasil e suas consequências na política de educação infantil. No censo demográfico de 1991, havia 13.122.136 crianças até três anos ( $9 \%$ da população) e 6.848.229 de quatro a cinco (5\%) e, em 2010, chegam a 10.925 .892 (6\%) e 5.802.254 (3\%), respectivamente. É fundamental ampliar a cobertura do atendimento e os investimentos em infraestrutura, de forma a garantir o direito à educação infantil, mas deve ser pensada a política em médio e longo prazos.

Em vista dessas considerações, abre-se um enorme campo de pesquisas na área de financiamento da educação no país. Como sugestão, aponta-se pesquisar o impacto das vinculações nos resultados alcançados, em vista dos objetivos da educação infantil. Alguns tipos de gastos são considerados de "educação" pelos órgãos de controle - Tribunais de Contas e Controladorias - e outros não. E mesmo considerado gasto de educação, muitas vezes há expressiva discricionariedade na aplicação dos recursos pelo município e como este é visto pelos próprios órgãos de controle.

Por outro lado, há tipos de gastos importantes para essa faixa etária que não são considerados vinculados à educação. A ampliação do acesso, em especial à creche, passa por modelos de financiamento que apoiem, por exemplo, a alimentação escolar; Cruz (2017) destaca que a alta adesão dos municípios ao programa Brasil Carinhoso está associada à possibilidade de custeio da alimentação e de cuidados e aos recursos não estarem vinculados aos limites de gastos com pessoal, como estabelece o Fundeb.

Assim, uma nova pergunta surge: as regras para acatar tanto a determinação constitucional de aplicação dos $25 \%$ de receitas como para utilização dos recursos do Fundeb contribuem para os municípios atingirem as metas do PNE? E, ainda, essas regras contribuem para a melhoria da qualidade da educação no país?

Ressalta-se que alguns tribunais de contas começam a se preocupar com a natureza dos gastos realizados na educação. O Tribunal de Contas de São Paulo, 
por exemplo, tem uma base de dados detalhada por município (função, subfunção, programa, ação, categoria, elemento, subelemento e outras especificidades), o que permite aprofundar o debate sobre os gastos na educação infantil.

Finalizando, este trabalho objetivou contribuir com informações sobre os gastos em educação infantil e auxiliar no planejamento da política educacional e na expansão do acesso ao direito à educação infantil. E trouxe, ainda, elementos para a reflexão e elaboração de novas pesquisas sobre os impactos do PNE nos municípios brasileiros.

\section{Referências bibliográficas}

ABRAHÃo, J. Financiamento e gasto público da educação básica no Brasil e comparações com alguns países da OCDE e América Latina. Educação \& Sociedade, Campinas, v. 26, n. 92, p. 841-858, out. 2005.

ARAúso, R. L. S. Desvendando o perfil dos gastos educacionais dos municípios brasileiros. Educação \& Sociedade, v. 33, n. 121, p. 1215-1233, 2012.

ARREtChe, M. T. da S. O processo de descentralização das políticas sociais no Brasil e seus determinantes. Campinas: Universidade de Campinas, 1998. Tese (doutorado) - Universidade de Campinas, Instituto de Filosofia e Ciências Humanas, Campinas.

Fiocruz, 2012.

Democracia, federalismo e centralização no Brasil. Rio de Janeiro: FGV;

BARros, R. P. de et al. Uma avaliação do impacto da qualidade da creche no desenvolvimento infantil. Pesquisa e Planejamento Econômico, Brasília, v. 41, n. 2, p. 211-230, ago. 2011.

BRASIL. Constituição da república federativa do Brasil. Portal da legislação - governo federal, 1988. Disponível em: <http://www.planalto.gov.br/ccivil_03/Constituicao/ Constituicao.htm>. Acesso em: 10 out. 2014.

Emenda Constitucional no 14, de 12 de setembro de 1996. Modifica os arts. 34, 208, 211 e 212 da Constituição Federal e dá nova redação ao Art. 60 do Ato das Disposições Constitucionais Transitórias. Portal da legislação - governo federal, 1996. Disponível em: <http://www.planalto.gov.br/ccivil_03/constituicao/ Emendas/Emc/emc14.htm>. Acesso em: 10 maio 2014.

. Lei no 9.394, de 20 de dezembro de 1996. Estabelece as diretrizes e bases da educação nacional. Portal da legislação - governo federal, 1996. Disponível em: <http://www.planalto.gov.br/ccivil_03/leis//9394.htm>. Acesso em: 15 jan. 2014.

Emenda Constitucional no 53, de 19 de dezembro de 2006. Dá nova redação aos arts. $7^{\circ}, 23,30,206,208,211$ e 212 da Constituição Federal e ao art. 60 do Ato das Disposições Constitucionais Transitórias. Portal da legislação - governo federal, 2006. Disponível em: <http://www.planalto.gov.br/ccivil_03/constituicao/ Emendas/Emc/emc53.htm>. Acesso em: 14 abr. 2014.

Ministério da Educação. Secretaria de Educação Básica. Política nacional de educação infantil: pelo direito das crianças de zero a seis anos à educação. 
Brasília: MEC, SEB, 2006. Disponível em: <http://portal.mec.gov.br/seb/arquivos/ pdf/pol_inf_eduinf.pdf>. Acesso em: 14 fev. 2015.

Projeto de lei do plano nacional de educação (PNE 2011/2020): projeto em tramitação no Congresso Nacional - PL no 8.035/2010. Disponível em: <http:// bd.camara.gov.br/bd/handle/bdcamara/5826>. Acesso em: 7 ago. 2012.

Lei no 11.494, de 20 de junho 2007. Regulamenta o Fundo de Manutenção e Desenvolvimento da Educação Básica e de Valorização dos Profissionais da Educação - Fundeb. Portal da legislação - governo federal, 2007. Disponível em: <http://www.planalto.gov.br/ccivil_03/_ato2007-2010/2007/lei//11494.htm>. Acesso em: 3 set. 2014.

Lei no 11.738 , de 16 de julho de 2008. Institui o piso salarial profissional nacional para os profissionais do magistério público da educação básica. Portal da legislação - governo federal, 2008. Disponível em: <http://www.planalto.gov.br/ ccivil_03/_ato2007-2010/2008/lei//11738.htm>. Acesso em: 14 out. 2014.

. Emenda Constitucional no 59, de 11 de novembro de 2009. Acrescenta $\S$ 3ㅇ ao art. 76 do Ato das Disposições Constitucionais Transitórias para reduzir, anualmente, a partir do exercício de 2009, o percentual da Desvinculação das Receitas da União incidente sobre os recursos destinados à manutenção e ao desenvolvimento do ensino de que trata o art. 212 da Constituição Federal, dá nova redação aos incisos I e VII do art. 208, de forma a prever a obrigatoriedade do ensino de quatro a dezessete anos e ampliar a abrangência dos programas suplementares para todas as etapas da educação básica, e dá nova redação ao $\S 4^{\circ}$ do art. 211 , ao $\S 3^{\circ}$ do art. 212 e ao caput do art. 214, com a inserção nesse dispositivo de inciso VI. Portal da legis/ação - governo federal, 2009. Disponível em: <http://www.planalto. gov.br/ccivil_03/constituicao/Emendas/Emc/emc59.htm>. Acesso em: 2 set. 2014.

. Lei no 12.499, de 29 de setembro de 2011. Autoriza a União a transferir recursos financeiros aos municípios e ao Distrito Federal, com a finalidade de prestar apoio financeiro à manutenção de novos estabelecimentos públicos de educação infantil. Portal da legislação - governo federal, 2011. Disponível em: <http://www. planalto.gov.br/ccivil_03/_Ato2011-2014/2011/Lei/L12499.htm>. Acesso em: 14 set. 2014.

BREMAEKER, F. E. J. A política de fundos para a educação e o impacto nas finanças dos Estados e municípios. In: GouveiA, A. B.; Pinto, J. M. R.; Corbuccl, P. R. (Orgs.). Federalismo e políticas educacionais na efetivação do direito à educação no Brasil. Brasília: Ipea, 2011. p. 51-68.

Campanha nacional pelo Direito À Educação. Portal custo aluno-qualidade inicial - CAQi \& custo aluno-qualidade CAQ. São Paulo, [201-]. Disponível em: <http:// www.custoalunoqualidade.org.br/calculos-do-caqi-e-do-caq>. Acesso em: 16 ago. 2016.

CAmpos, M. M. M. Educação infantil: o debate e a pesquisa. Cadernos de Pesquisa, São Paulo, v. 11, p. 113-127, 1997.

CAVAlieri, C. H.; PAzello, E. T. Efeito distributivo das políticas sociais. In: BIDERMANN, C.; ARVATE, P. Economia do setor público no Brasil. Rio de Janeiro: Elsevier, 2004. p. 
$339-351$.

CRUZ, M. do C. M. T. Implementação da política de creches nos municípios brasileiros após 1988: avanços e desafios nas relações intergovernamentais e intersetoriais. São Paulo: FGV, 2017. Tese (Doutorado) - Escola de Administração de Empresas de São Paulo, Fundação Getulio Vargas, São Paulo.

Cruz, M. do C. M. T.; FARAH, M. F. S.; SugiYAMA, N. B. Normatizações federais e a oferta de matrículas em creches no Brasil. Estudos em Avaliação Educacional, São Paulo, v. 25, n. 59, p. 202-241, set./dez. 2014.

CURI; A. Z.; MENEZES-FILHO, N. A. A relação entre educação pré-primária, salários, escolaridade e proficiência escolar no Brasil. Estudos Econômicos, São Paulo, v. 39, n. 4, p. 811-850, 2009. Disponível em: <http://www.scielo.br/pdf/ee/v39n4/05. pdf>. Acesso em: 25 maio 2014.

Fundação Prefeito faria lima (Cepam); FundaçÃo do DesenVolvimento AdMINISTRATIVo (Fundap); FundAÇÃo SISTEMA ESTADUAL DE ANÁlISE E DAdos (Seade). Elementos para a melhoria das condições de oferta de educação infantil no estado de São Paulo - Relatório Final, v. 1, v. 2, v. 3. 2013.

FUndAÇÃo SISTEMA ESTADUAL DE ANÁLISE DE DAdos (Seade). Estimativas populacionais de 2011 a 2020, matrículas. Disponível em: <http://produtos.seade.gov.br/ produtos/projpop/>.

Fundo nacional de Desenvolvimento da Educação (FNDE). Sistema de Informações sobre Orçamentos Públicos em Educação (Siope). Portal do FNDE, Brasília, 2016. Disponível em:<https://www.fnde.gov.br/siope/ indicadoresFinanceirosEEducacionais.do>. Acesso em: 26 abr. 2016.

HECKMAN, J. J. Skill formation and the economics of investing in disadvantaged children. Sciense, Washington, DC, v. 312, n. 5782, p. 1900-1902, 2005.

KRAMER, S. As crianças de 0 a 6 anos nas políticas educacionais no Brasil: educação infantil e/é fundamental. Revista Educação \& Sociedade, Campinas, v. 27, n. 96 Especial, p. 797- 818, out. 2006.

Montoro, F. Por que tributar? Série Projeto Educação Fiscal para a Cidadania Cepam/Escola Fazendária do Estado, São Paulo, p. 15-19, 2013.

PINTO, J. M. R. Federalismo, descentralização e planejamento da educação: desafios aos municípios. Cadernos de Pesquisa, São Paulo, v. 44, n. 153, p. 624-644, set. 2014.

Salomão, F. S.; Magalhães, J.; Cruz, M. do C. M. T.; SelXas, S. M. T. Prefeitos paulistas: gestão 2013-2016. São Paulo: Cepam, 2014.

SANTOS, D. D. dos. Influência do efeito da educação infantil sobre a desigualdade. In: LABORATÓRIO DE ESTUdOS E PESQUISAS EM ECONOMIA SOCIAL. Educação infantil no Brasil. Ribeirão Preto: FEA/USP/RP, 2015.

SeCretaria do Tesouro Nacional. Contas anuais. Execução orçamentária dos municípios - 2012. Disponível em: <https://www.tesouro.fazenda.gov.br/pt/ component/content/article/48-prefeituras-governos-estaduais/767-contasanuais>. Acesso em: 3 mai. 2015. 
SHONKOFF, J. P. Proteger o Cérebro, e não apenas estimular as Mentes. Sciense, v. 33, 19 agosto de 2011. Disponível em: < http://www.fmcsv.org.br/pt-br/acervodigital/Paginas/Proteger-os-C\%C3\%A9rebros,-N\%C3\%A3o-Apenas-Estimular-asMentes-Jack-P.aspx>. Acesso em: 15 jun. 2014.

SouzA, A. P. Impactos da pré-escola no Brasil. In: Araúso, Aloísio Pessoa de (Coord.). Aprendizagem infantil: uma abordagem da neurociência, economia e psicologia cognitiva. Rio de Janeiro: Academia Brasileira de Ciências, 2011. p. 231-246.

VELOSO, F. A evolução recente e propostas para a melhoria da educação no Brasil. In: BACHA, E. L.; SCHWARTZMAN, S. (Orgs.). Brasil: a nova agenda social. Rio de Janeiro: LTC, 2011. p. 216-253. Disponível em: <http://www.schwartzman.org.br/simon/ agenda8.pdf>. Acesso em: 16 jun. 2014.

\section{Maria do Carmo Meirelles Toledo Cruz}

Doutora em Administração Pública e Governo pela Escola de Administração de Empresas de São Paulo da Fundação Getulio Vargas; professora da Pós-graduação da Escola do Parlamento da Câmara Municipal de São Paulo; secretária executiva do Instituto para o Desenvolvimento de Inovações Tecnológicas, Sociais, Gestão de Políticas Públicas e Justiça Social (Instituto JUS) e ex-técnica da Fundação Prefeito Faria Lima - Centro de Estudos e Pesquisas de Administração Municipal (Cepam).E-mail: carminhameirelles@gmail.com.

\section{Fátima Fernandes Araújo}

Administradora de Empresas pela Pontifícia Universidade Católica de São Paulo e ex-coordenadora de Gestão e Políticas Públicas do Cepam. E-mail: araujofatima59@gmail.com

\section{Carlos Corrêa Leite}

Pós-graduado em Controladoria em Gestão Pública, pela Fundação Instituto de Pesquisas Contábeis, Atuariais e Financeiras da Universidade de São Paulo (Fipecafi-USP), técnico da Secretaria de Desenvolvimento Regional do Estado de São Paulo e ex-técnico do Cepam. E-mail: ccleite1950@gmail.com

\section{Fernando Antônio Franco Montoro}

Doutor em Integração da América Latina pela USP, assessor do secretário de Desenvolvimento Regional do estado de São Paulo, professor da Universidade São Caetano do Sul e ex-coordenador de Gestão e Políticas Públicas do Cepam.E-mail: fernandomontoro@uol.com.br 